\title{
Asymptomatic pulmonary cement embolism
}

\author{
Chun-Yung Chang MD, Shu-Fang Huang MD
}

Cite as: CMAJ 2017 April 10;189:E543. doi: 10.1503/cmaj.160579

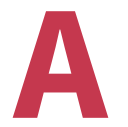

59-year-old man presented for follow-up of an abnormal chest radiograph (Figure $1 \mathrm{~A}$ ), which had been ordered as part of a routine health examination. One year prior, he had sustained a compression fracture and traumatic spondylolisthesis because of a car accident. Treatment included percutaneous vertebroplasty at L3 and pedicle screw augmentation at L5 and S1.

The patient did not have fever, dyspnea, cough or hemoptysis. There was no tenderness in the chest wall, and breath sounds were normal bilaterally. Computed tomography of the chest showed multiple linear hyperdense foreign bodies at the pulmonary arteries bilaterally. Radiography of the lumbar spine showed previous
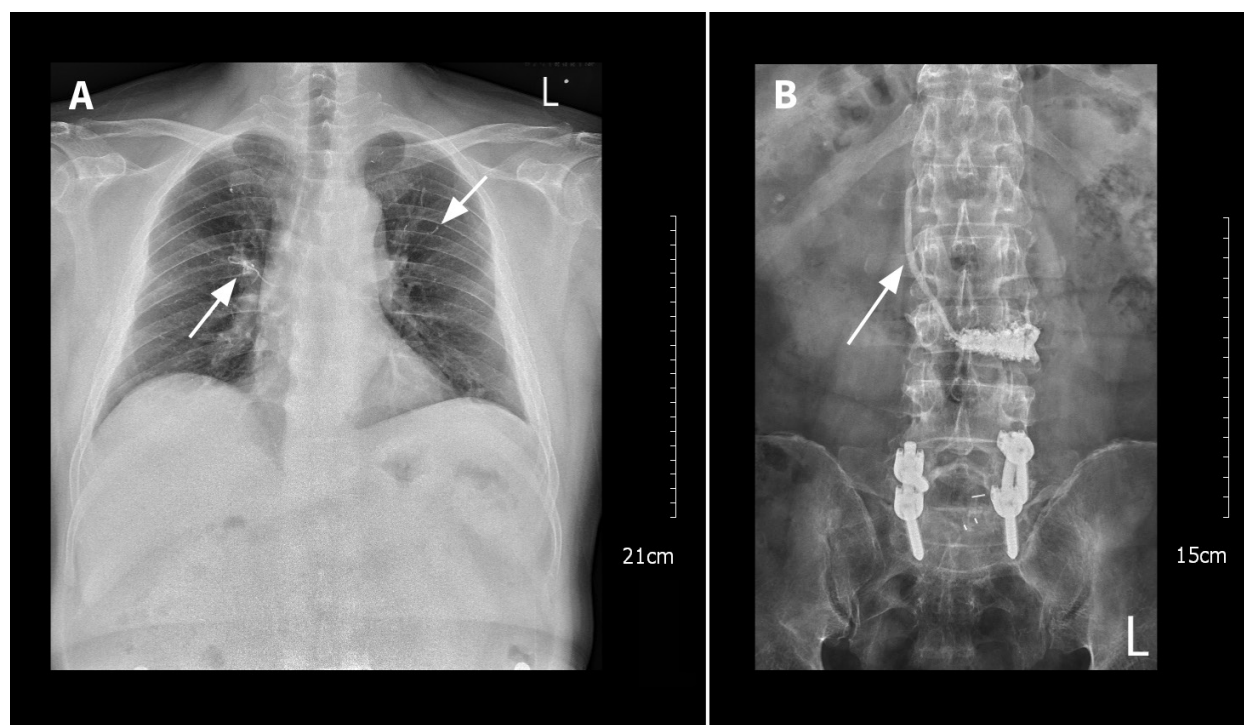

Figure 1: (A) Chest radiograph in a 59-year-old man showing linear high-density lesions near the right hilar area (thick arrow) and bilateral lung fields (thin arrow). (B) Plain film radiograph of the lumbar spine showing previous cement vertebroplasty at L3 and pedicle screw augmentation at L5 and S1. Migration of cement into the ascending lumbar vein (arrow) at L3 can be seen. vertebroplasty at L3 with cement migration via the ascending lumbar vein (Figure 1B). Because of the extensive distribution of cement, we offered the patient anticoagulation treatment, which he agreed to, after a discussion of the uncertainties and possible complications of this treatment.

Pulmonary cement embolism is a known complication of vertebroplasty. ${ }^{1}$ Bone cement may migrate into the vertebral venous plexus and from there, it can enter the thoracic, followed by the pulmonary, venous systems. ${ }^{1}$ Incidence estimates vary widely from $2 \%$ to $26 \% .{ }^{2}$ The management of asymptomatic pulmonary cement embolism remains uncertain; our decision was informed by an analysis of a case report by Krueger and colleagues that suggested anticoagulation treatment only for centrally distributed

emboli. ${ }^{3}$ In situations where there is limited, poor-quality evidence, as in this case, decision-making may be complex, variable and often dependent on the values and preferences of the patient.

\section{References}

1. Groen RJ, du Toit DF, Phillips FM, et al. Anatomical and pathological considerations in percutaneous vertebroplasty and kyphoplasty: a reappraisal of the vertebral venous system. Spine 2004;29:1465-71.

2. Wang LJ, Yang HL, Shi YX, et al. Pulmonary cement embolism associated with percutaneous vertebroplasty or kyphoplasty: a systematic review. Orthop Surg 2012;4:182-9.

3. Krueger A, Bliemel C, Zettl R, et al. Management of pulmonary cement embolism after percutaneous vertebroplasty and kyphoplasty: a systematic review of the literature. Eur Spine $J$ 2009;18:1257-65.

\footnotetext{
Competing interests: None declared.

This article has been peer reviewed.

The authors have obtained patient consent.

Affiliation: Internal Medicine Department, Kaohsiung Armed Forces General Hospital, Lingya District, Kaohsiung City, Taiwan (R.O.C.)
}

Correspondence to: Chun-Yung Chang, alpha1320@gmail.com 